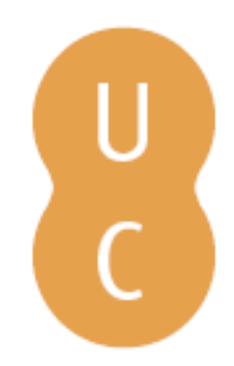

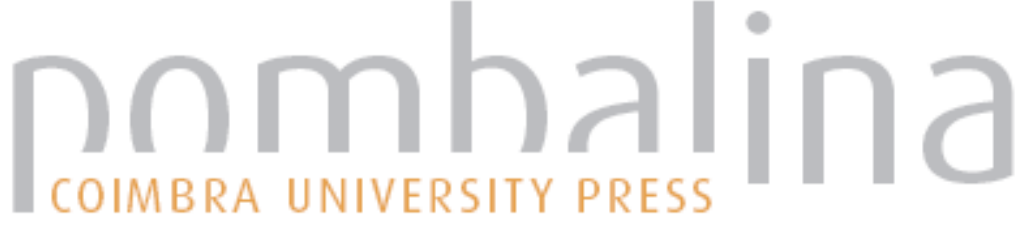

\section{Plano para centro comunitário na faixa central da llha}

Autor(es): $\quad$ Brito, Aldevina; Mendonça, Lisandra Franco de

Publicado por: Imprensa da Universidade de Coimbra

URL

persistente: URI:http://hdl.handle.net/10316.2/44315

DOI: $\quad$ DOI:https://doi.org/10.14195/978-989-26-1556-1_10

Accessed : $\quad$ 26-Apr-2023 14:30:02

A navegação consulta e descarregamento dos títulos inseridos nas Bibliotecas Digitais UC Digitalis, UC Pombalina e UC Impactum, pressupõem a aceitação plena e sem reservas dos Termos e Condições de Uso destas Bibliotecas Digitais, disponíveis em https://digitalis.uc.pt/pt-pt/termos.

Conforme exposto nos referidos Termos e Condições de Uso, o descarregamento de títulos de acesso restrito requer uma licença válida de autorização devendo o utilizador aceder ao(s) documento(s) a partir de um endereço de IP da instituição detentora da supramencionada licença.

Ao utilizador é apenas permitido o descarregamento para uso pessoal, pelo que o emprego do(s) título(s) descarregado(s) para outro fim, designadamente comercial, carece de autorização do respetivo autor ou editor da obra.

Na medida em que todas as obras da UC Digitalis se encontram protegidas pelo Código do Direito de Autor e Direitos Conexos e demais legislação aplicável, toda a cópia, parcial ou total, deste documento, nos casos em que é legalmente admitida, deverá conter ou fazer-se acompanhar por este aviso.

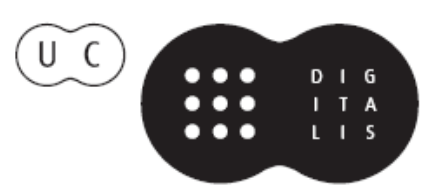




\section{OFICINAS DE \\ MUHIPITI \\ planeamento estratégico \\ património \\ desenvolvimento}

organização:

Walter Rossa

Nuno Lopes

Nuno Simão Gonçalves

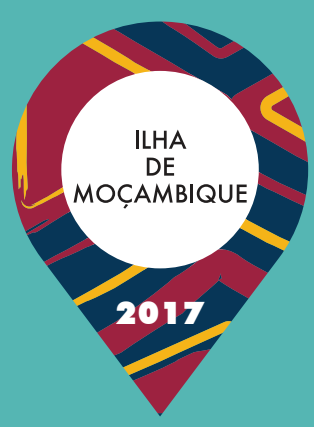




\title{
PLANO PARA CENTRO COMUNITÁRIO NA FAIXA CENTRAL DA ILHA
}

\author{
Aldevina Brito \\ Lisandra Franco de Mendonça
}

\section{Missão-encomenda previamente formulada}

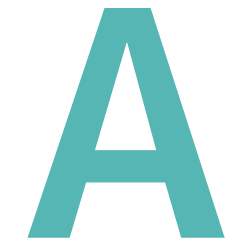

faixa situada sensivelmente no centro da llha, definida no sentido norte sul pela extensão do edifício do hospital e compreendida no sentido este-oeste entre ambas as costas, marca a articulação entre a dita cidade de pedra e cal e o bairro de macuti. É hoje um emaranhado de ruínas, espaços residuais e informalmente apropriados públicos e privados, edifícios desaproveitados de grande potencial (a começar pelo do Hospital), mas também um espaço de reunião e encontro da comunidade local, uma espécie de fórum que carece de clarificação de usos e espaços. Pretende-se que esta oficina faça um levantamento circunstanciado de toda essa complexa realidade e proponha um ou mais cenários de reurbanização do conjunto e reabilitação das suas construções e espaços por forma a que esse caráter de centro cívico surja de forma clara. 
Nos alvores da Guerra Colonial/de Libertação (1964-1974), o governo central mandou edificar, por entre a vegetação densa do antigo jardim e viveiro do Largo Afonso de Albuquerque, um pequeno edifício térreo de duas águas, com alpendre de acesso disposto a norte, afeto à escola primária para raparigas. A reprodução deste tipo de escolas, a partir de meados da década de 1950, procurava reformular a abrangência do ensino nas várias cidades da província. O seu desenho assentava na resolução dos problemas de adaptação climática dos edifícios, da expressão modular dos elementos estruturais e dos sistemas construtivos, apresentando, no geral, algumas características constantes, nomeadamente a implantação, alheia à orientação do tecido urbano e aos "limites do terreno orientando-se antes segundo os pontos cardeais" (Miranda, 2013: 236).

No centro do largo foi erigido (c. 1966) um monólito irregular de pedra, do escultor Helder Batista (1932-2015), com a efígie de Luís de Camões e uma dedicatória ao IV centenário da estadia do poeta na Ilha (14691969) na face longa virada para o oceano, e um soneto de Os Lusíadas, no lado curto virado a nordeste. O memorial, renomeado localmente Pedra Sagrada ou Monumento Afonso de Albuquerque e a escola primária, foram algumas das muitas obras inauguradas, em 1969, na Ilha e continente fronteiro, pelo governador-geral Baltazar Rebelo de Sousa, por ocasião das Comemorações dos Centenários (ARPAC, Cx. Nampula, XI, Monumentos e Locais Históricos, 4).

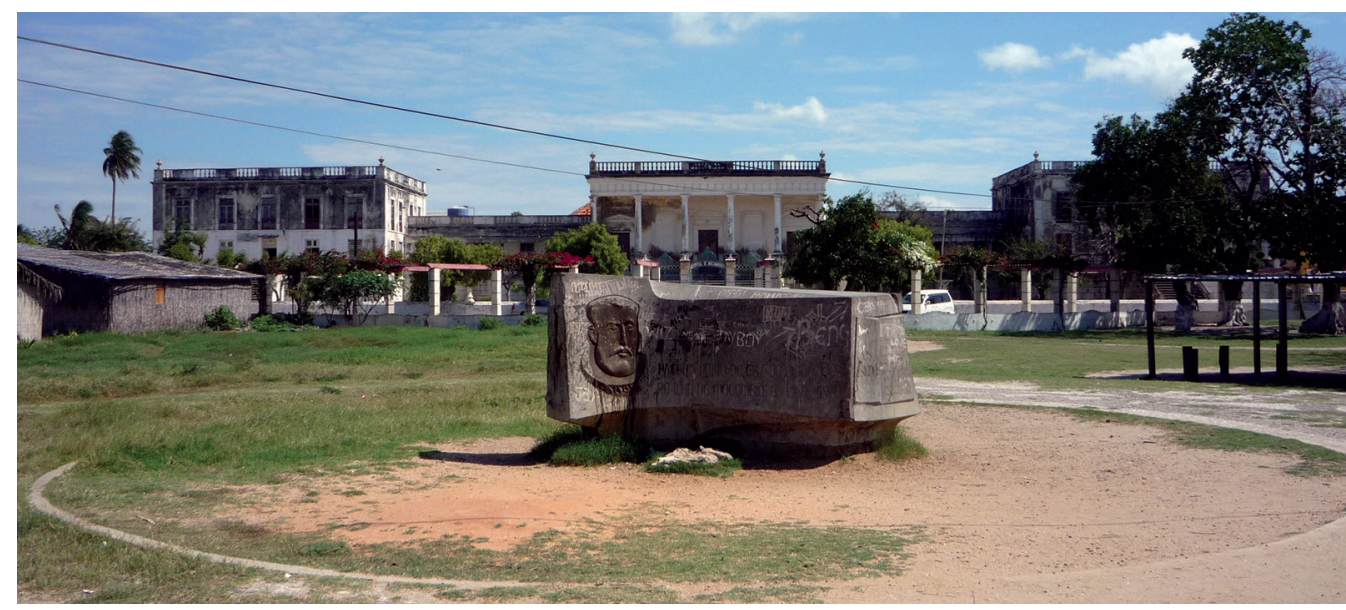




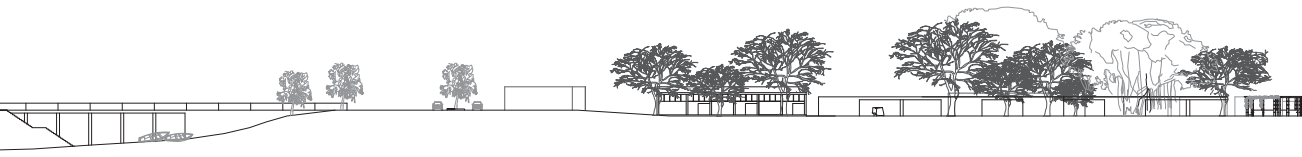

Com a Independência, a escola, renomeada 16 de Junho, recebeu um segundo volume isolado e símile ao primeiro, de construção mais modesta, e a área em torno foi amurada. Já antes, o muro de contenção e a subida de cotas na frente marítima a este, para contrapor o desgaste provocado pela violência das marés, alterara definitivamente a relação visual entre o antigo largo (abaixo do nível do mar) e a linha de água. Desapareciam também grande parte das casuarinas usadas para fixar as dunas nesse lado da costa.
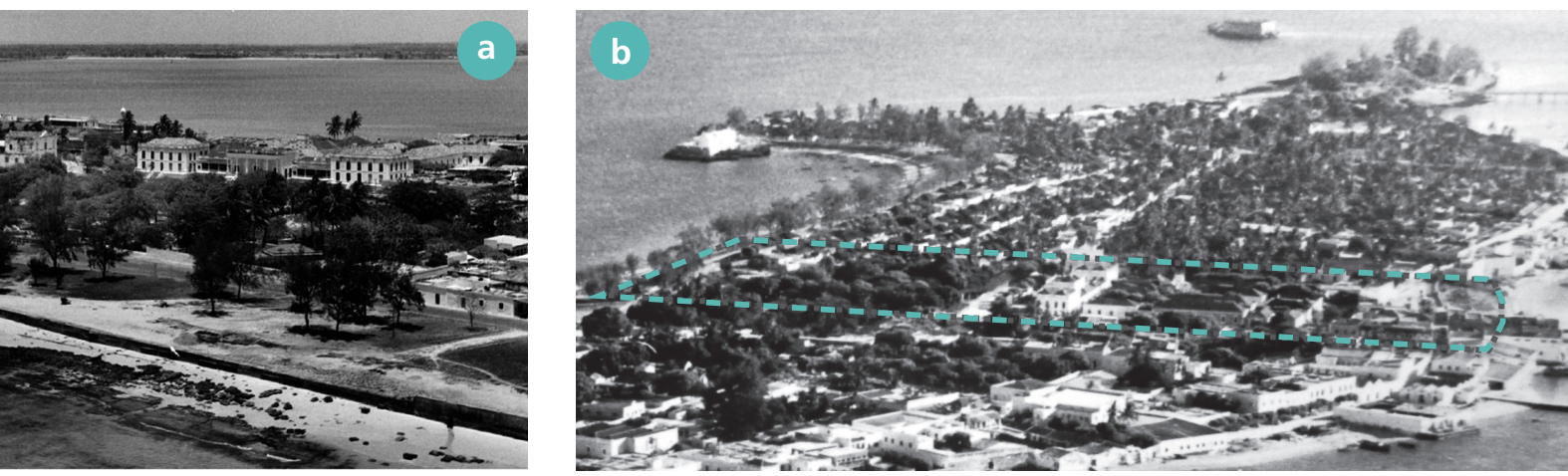

Excerto de fotografias aéreas da Ilha de Moçambique, 1974:

a) área do Hospital de Moçambique e do Largo Afonso de Albuquerque;

b) área de estudo.
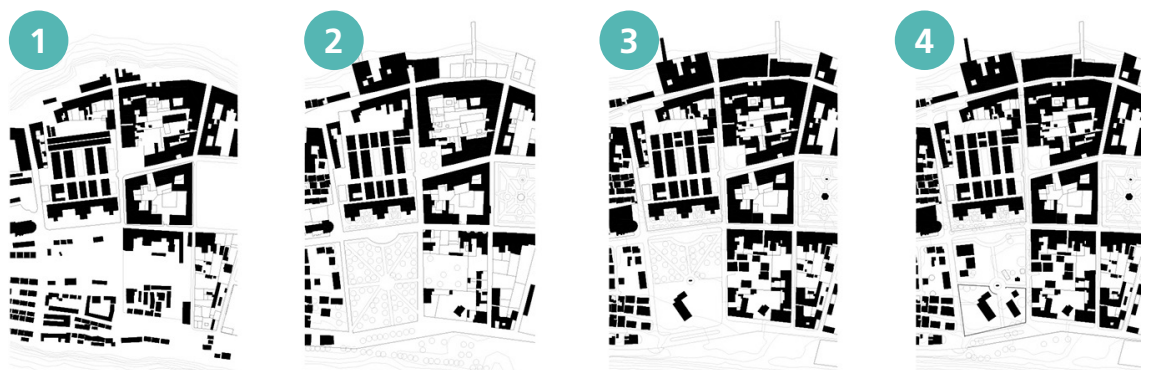

Representação esquemática da evolução da ocupação na área de estudo:

1) final do século $X I X$;

2) meados do século $X X$;

3) final da década de 1960;

4) situação atual. 


\section{O CENTRO COMUNITÁRIO}

O estudo desta oficina teve por base o trabalho de campo e a pesquisa histórico-social efetuada previamente e no local. Realizaram-se entrevistas a cabeças de família dos vários bairros da cidade de macuti e a alguns líderes espirituais da comunidade, sobre a pertinência de vários elementos dispersos existentes na área de intervenção e suas imediações (i. e., a Escola Primária 16 de Junho; o poço confinado ao logradouro de um restaurante da Praça 16 de Junho e que outrora abastecia o jardimviveiro; vários locais de culto, nomeadamente a Mesquita Grande e a das Palmeiras e a Igreja de Nossa Senhora da Saúde), possibilidades de requalificação dos espaços e aspirações urbanas dos habitantes.

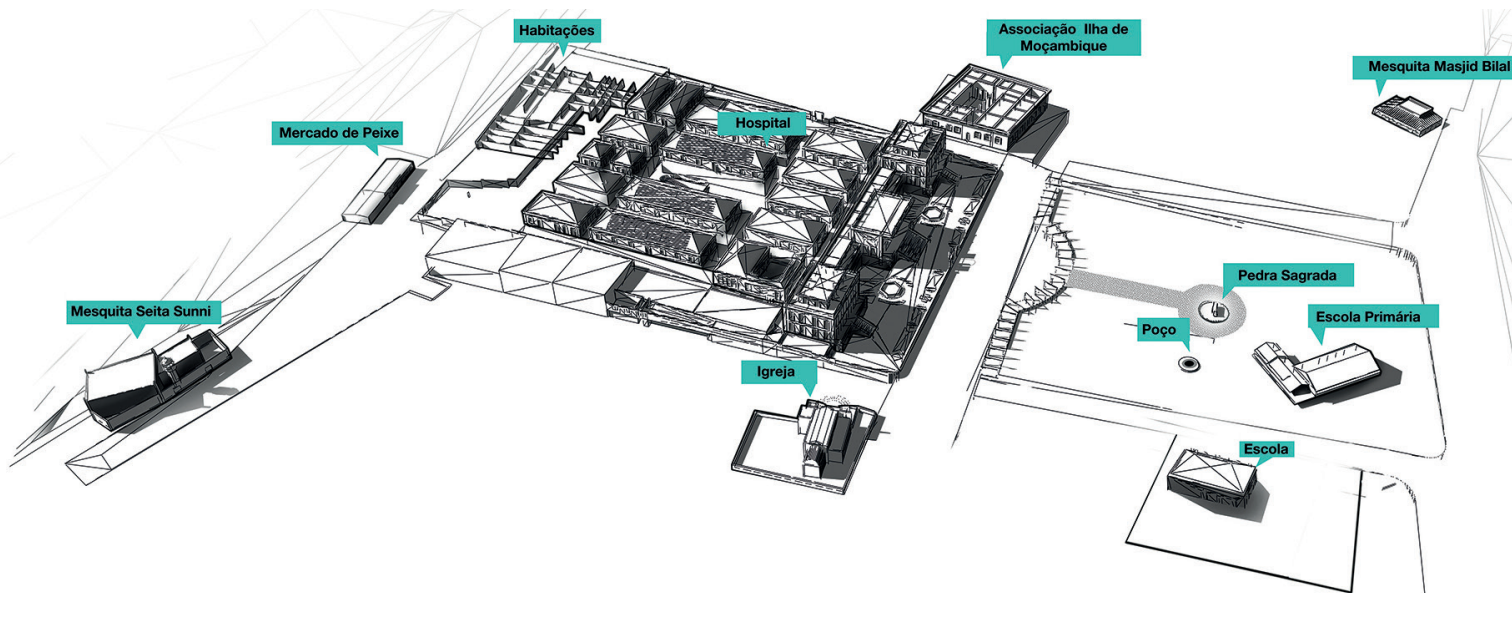

Apesar de a discussão ter privilegiado, inicialmente, o aproveitamento de alguns pavilhões desocupados do hospital para outras funções com o serviço relegado atualmente ao nível de centro de saúde —, no seguimento dos trabalhos, e de acordo com informações recebidas, esse estudo foi abandonado. Averiguou-se que o hospital, a carecer de obras urgentes, foi objeto de um projeto de reabilitação, a cargo do Ministério da Saúde, e que a execução faseada das obras, iniciada recentemente, abrangerá o inteiro complexo. Restou-nos extrapolar que a refuncionalização parcial daquele equipamento para a instalação, por exemplo, de uma instituição académica - a conformação e a situação 
de cal, sobrelevado por meio de um embasamento, tem a composição e tecnologia típicas das casas de influência indo-portuguesa comuns na Ilha: linhas simples numa planta retangular composta por várias dependências que constituíam os quartos de dormir e salas de estar e comer, e uma zona de serviço (com sanitários, cozinha e cisternas) no tardoz, numa cerca de tipo pátio. A entrada principal, sobre a Avenida dos Heróis, faz-se através de um alpendre do tipo colunata e colunas de alvenaria com arestas vivas formando uma varanda larga, onde se apoia a escada de amplos corrimãos.

Para além da pertinência do programa desta associação, as obras em curso no edifício-sede permitiram à oficina apreciar técnicas de construção tradicionais em risco de caírem em desuso. No estaleiro, foram construídos dois tanques de queima de cal para a preparação tradicional de cal apagada/hidratada a utilizar nas argamassas e rebocos da obra; a cobertura do edifício foi refeita repondo a estrutura de troncos encastoados na espessura das paredes-mestras colocados no sentido de menor vão, sobrepostos por uma espécie de esteira de varas mais delgadas, onde se assenta areão grosso e argamassa de cal, terra arenosa e, por último, betonilha de cal e areia misturada com óleo de murrapa. Para além destes trabalhos, os de marceneiro e ebanista no mobiliário do edifício, têm sido executados com primor por membros da associação.

O domínio das tecnologias construtivas ancestrais e a resiliência destas artes são um património vivo de Moçambique. O conhecimento históricocrítico desse património permite-nos enfatizar que essas práticas se traduziram na llha como provavelmente em nenhum outro local de Moçambique, na "mais completa síntese de culturas arquitecturais [...], no que traduz com exactidão e complexidade, sedimentação e síntese das suas estruturas sociais" (apud Fonseca, 1968: 48).

Além deste novo equipamento cultural situado às portas da Praça 16 de Junho, advinha-se a abertura do Centro de aprendizagem Ozuela Wixutta, idealizado e financiado por um privado, no Bairro de Santo António. Organizado em duas casas de macuti interligadas por pequenos pátios, esse espaço multiusos tem o foco nas mães do bairro e nos jovens, maioritariamente sem ocupação. O centro ministrará cursos de culinária, cerâmica, pintura, costura, etc., conciliando espetáculos de música, dança e teatro. 
Ao longo do limite sul da praça, esboçou-se um edifício térreo sob uma longa pala, esplanadas e vários atravessamentos, para instalar os restaurantes que ali se encontram e alguns serviços de apoio (sanitários públicos, quiosque, armazém e casa do jardineiro). Propôs-se a demolição do volume mais recente da Escola Primária 16 de Junho (transferindo essa função para o edifício da antiga escola primária situado nas imediações da praça, a sul, devidamente reabilitado e ampliado) e do muro de vedação. Ensaiou-se, nessa área, a reposição das árvores e o aproveitamento da subida suave de cotas em direção à costa este para a criação de uma espécie de anfiteatro natural, onde a população possa assistir, sentada na relva, a eventos de carácter efémero, como cinema ao ar livre, reuniões comunitárias, entre outros.

A proposta de repor as espécies arbóreas e a vegetação densa da praça abrange as ruas adjacentes, nomeadamente os carreiros de casuarinas ao longo do arruamento e das dunas da costa a este. A plantação de árvores deve seguir uma investigação sobre as espécies existentes em cada local e sua antiga proveniência (estas marcavam distintamente a paisagem, tendo os habitantes referido espécies e proveniências várias do Índico), a registar nos vários locais com sinalética própria.

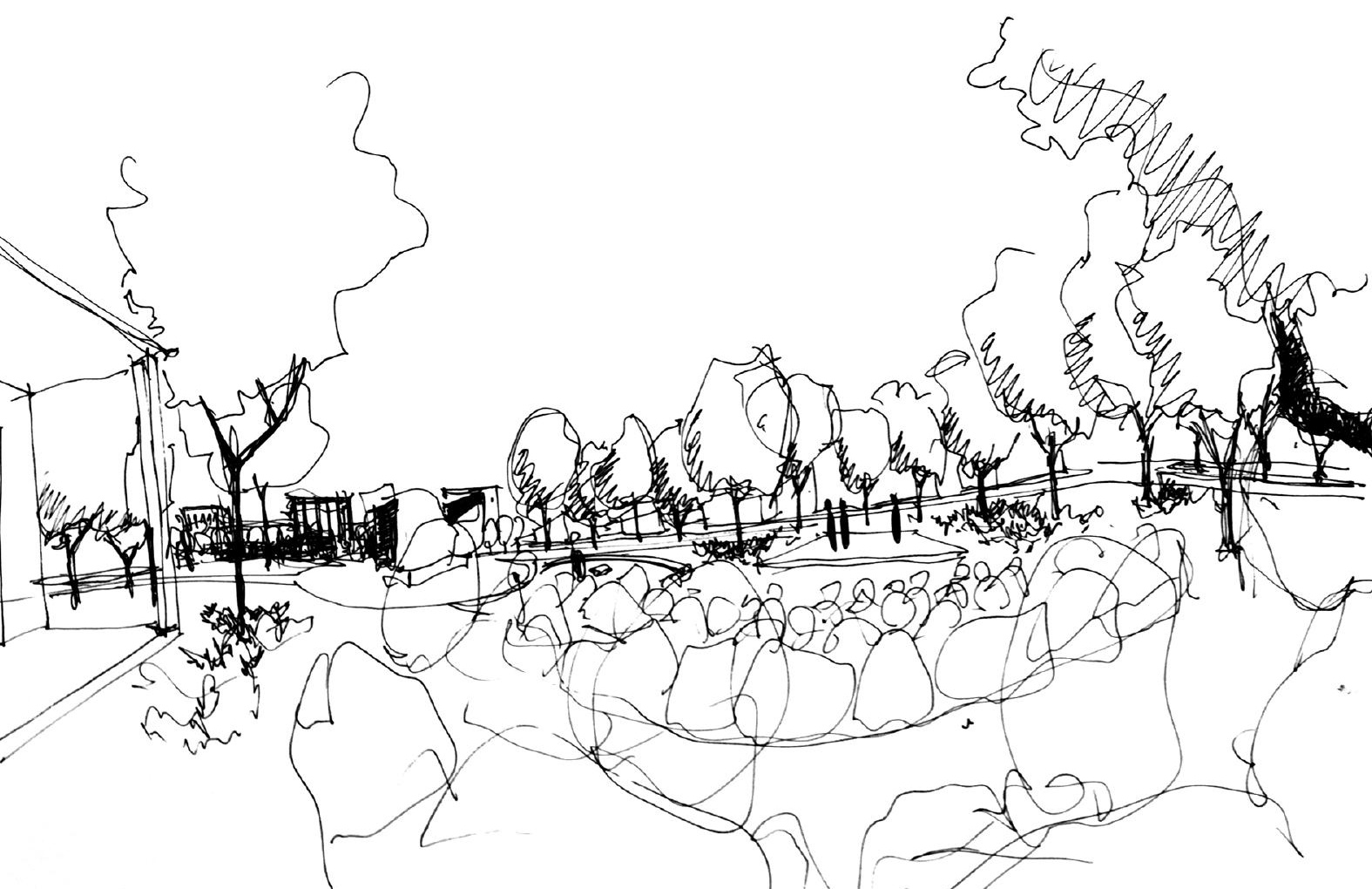


No espaço limitado para esta apresentação, optou-se por uma síntese da investigação da oficina. A relevância deste intercâmbio, no entanto, passa pelo seu impacto na averiguação de boas práticas para o património da llha, procurando "como próprios da terra, de habitá-la" (excerto de Os Lusíadas entalhado na Pedra Sagrada, na Praça 16 de Junho), reconhecê-la e conservá-la.

\section{LEGENDA}

\begin{tabular}{|c|c|c|}
\hline Escola Primária & Anfiteatro aberto & Pedra sagrada \\
\hline Hospital & Proposta para casas Docentes & Mercado de Peixe \\
\hline Área de Restauração & Atual Centro comunitário & Pontão \\
\hline Igreja & Espaço de exposição & \\
\hline
\end{tabular}
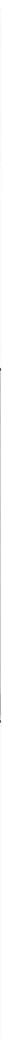


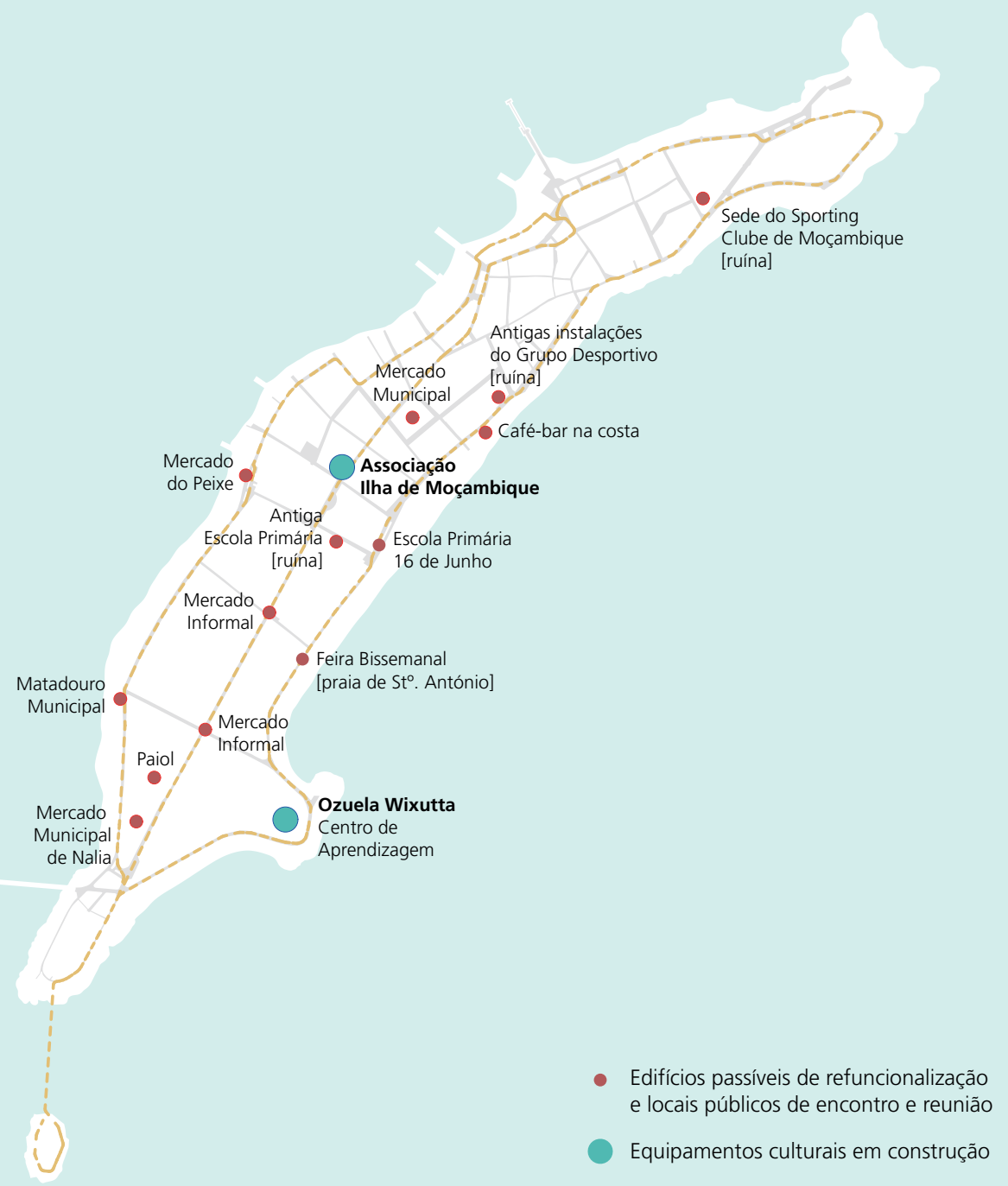




\section{REFERÊNCIAS BIBLIOGRÁFICAS}

Arquivo do Património Cultural/ Instituto de investigação Sociocultural, CX. Nampula, XI, Monumentos e Locais Históricos, 4

FONSECA, Pedro Quirino da (1968), "Breves notas sobre a evolução da habitação e construção em Moçambique", Monumenta: Publicação da Comissão dos Monumentos Nacionais de Moçambique, (4), 45-48. MACHADO, Joaquim José (1879), "Relatório dos trabalhos executados pela direcção das obras públicas da província de Moçambique durante o anno de 1877", Relatórios dos Directores de Obras Públicas e Outros Documentos 1876-81, Primeira Série. Lisboa: Imprensa Nacional, 91-131.

MIRANDA, Elisiário (2013), Liberdade \& Ortodoxia: Infraestruturas de arquitetura moderna em Moçambique (1951-1964). Dissertação de doutoramento apresentada à Escola de Arquitetura da Universidade do Minho, Guimarães.

MORAIS, João Sousa (2001), Maputo, património da estrutura e forma urbana, topologia do lugar. Lisboa: Livros Horizonte.

Portaria n. ${ }^{\circ} 15$ 366, de 3 de maio de 1955. Boletim Oficial n. ${ }^{\circ} 22$, I Série, de 28 de maio de 1955. Direcção Geral de Administração Política e Civil (classifica o conjunto urbano da "cidade de pedra e cal" da llha de Moçambique). 